\title{
Three months in a high-volume tertiary orthopaedic trauma unit: What is a registrar worth?
}

\author{
H F van Zyl, MB ChB; M Burger, BSc, B(Med)Sc Hons, M(Med)Sc, PhD; N Ferreira, BSc, MB ChB, FCOrth (SA), MMed (Orth), PhD \\ Division of Orthopaedic Surgery, Department of Surgical Sciences, Faculty of Medicine and Health Sciences, Stellenbosch University, \\ Cape Town, South Africa
}

Corresponding author: N Ferreira (nferreira@sun.ac.za)

Background. South Africa has a high burden of traumatic injuries that is predominantly managed in the public healthcare system, despite the relative disparity in human resources between the public and private sectors. Because of budget and theatre time constraints, the trauma waiting list often exceeds 50 - 60 patients who need urgent and emergent surgery in high-volume orthopaedic trauma centres. This situation is exacerbated by other surgical disciplines using orthopaedic theatre time for life-threatening injuries because of lack of own theatre availability. One of the proposed solutions to this problem is outsourcing of some of the cases to private medical facilities.

Objectives. To establish the volume of work done by an orthopaedic registrar during a 3-month trauma rotation, and to calculate the implant and theatre costs, as well as compare the salary of a registrar with the theoretical private surgeon fees for procedures performed by the registrar in the 3-month period.

Methods. In a retrospective study, the surgical logbook of a single registrar during a 3-month rotation, from 14 January to 14 April 2019 , was reviewed. Surgeon fees were calculated for these procedures, according to current medical aid rates, without additional modifier codes being added.

Results. During the 3-month study period, a total of 157 surgical procedures was performed, ranging from total hip arthroplasty to debridement of septic hands. Surgeon fees amounted to ZAR186 565.10 per month - double the gross salary of a registrar. Total implant costs amounted to ZAR1 272667 . Theatre costs were ZAR1 301976 for the 3-month period.

Conclusions. Although this analysis was conducted over a short period, it highlights the significant amount of trauma work done by a single individual at a high-volume tertiary orthopaedic trauma unit. With increasing budget constraints, pressure on theatre time and a growing population, cost-effective expansion of resources is needed. From this study, it appears that increasing capacity in the state sector could be cheaper than private outsourcing, although a more in-depth analysis needs to be conducted.

S Afr Med J 2021;111(5):482-486. https://doi.org/10.7196/SAMJ.2021.v111i5.14844

South Africa (SA) is a unique country with large discrepancies between the public and private sector medical infrastructure. A 2015 health policy project reported that $84 \%$ of the population was served in the public sector compared with only $16 \%$ in the private sector. In stark contrast, the report highlighted that the SA private sector accounted for $49.8 \%$ of the total health expenditure. ${ }^{[1]}$

SA's healthcare systems have to manage a heavy burden of interpersonal violence and road traffic accidents. A 2007 report found that SA men had an 8.2 higher mortality rate than their global counterparts, secondary to interpersonal violence. ${ }^{[2]}$ The frequency of unnatural death peaks in young individuals aged 20 - 24 years, accounting for $49.9 \%$ of cases. The overall rate of morbidity and mortality with external causes was $11.5 \%$, as reported by Statistics SA in 2017. ${ }^{[3]}$ In recent years, an increase in gang violence in Western Cape Province, which has subsequently led to an increase in interpersonal morbidity and mortality, has been well documented in the media. ${ }^{[4]}$ In response to the increase in violence, the SA National Defence Force was deployed in July 2019 with the aim of stabilising various affected areas - subsequently reducing gang-related violence. Although the efficacy of this intervention remains to be established, it highlights the magnitude of the problem, directly on society and indirectly on healthcare facilities. A local study published in 2017 highlighted the orthopaedic burden of gunshot-related injuries at a tertiary centre and found that 111 patients needed orthopaedic procedures during a 1-year period in $2012 .{ }^{[5]}$
The Western Cape population is growing disproportionally to the estimated country population growth of $1.43 \%$. The province is second only to Gauteng in terms of in-migration, with an estimated net migration of 316308 people between 2016 and 2021, ${ }^{[6]}$ further compounding population growth and the demand for medical services.

To manage this demand, in 2018, SA had 897 orthopaedic surgeons, of whom $81 \%$ were in private practice. The Western Cape had 229 orthopaedic surgeons; 177 of these were in private practice, with a surgeon-to-patient ratio of 11:100 000 compared with 0.9:100 000 in the public sector. ${ }^{[7]}$ Orthopaedic registrars perform a large percentage of trauma surgery, which is always done with direct supervision or availability of senior surgeons for assistance and quality assurance.

The health sector budget for the Western Cape increased by only $7.3 \%$ during $2018-2019,{ }^{[8,9]}$ with the annual increase being offset by the population growth and increased cost of care, which are directly related to implant and consumable costs. In 2016, the Western Cape Department of Health secured a 3-year tender contract, with predetermined prices for implants. The yearly increases vary from 3 -year fixed prices to annual increases of $10.3 \%$, with most companies annually increasing prices between $4.5 \%$ and $10 \% \cdot{ }^{[10]}$ However, with a deterioration of $33 \%$ in the exchange rate from April 2017 to March 2020, and the current economic climate, further increases can be expected. 
Due to the large trauma load, suggested solutions included possible outsourcing to private hospitals. This also concurs with the Government Gazette of June 2017, relating to the National Health Insurance Policy, ${ }^{[11}$ which alluded to the purchasing of services from private hospitals and specialists, as well as regulating consumable costs.

The aim of this study was to establish the volume of work an average orthopaedic trauma registrar performs over a 3-month period. Secondary aims were to calculate the cost of care in terms of surgeon fee, implant cost and theatre cost for all patients managed during this period. Finally, we aimed to compare the gross salary of an orthopaedic registrar with the theoretical remuneration a surgeon would receive if these operations were performed in a private sector setting to calculate what an orthopaedic registrar is worth in private healthcare terms.

\section{Methods}

This investigation followed a retrospective design, comprising all surgical procedures performed by a single orthopaedic trauma registrar at a government sector tertiary hospital in the Western Cape, SA, during a 3-month period.

All procedures were coded and billed according to medical aid rates, as per the Government Employees Medical Scheme (GEMS) tariff codes of 2017 $7^{[12]}$ and billing guideline of the SA Orthopaedic Association (SAOA). ${ }^{[13]}$ Only the primary surgeon fee was calculated, even though an assistant might have been present. Basic billing of procedures was performed by including only the primary procedure and the addition of minimal secondary codes, e.g. debridement of open injuries associated with internal fixation and surgeon consultation fee. No additional coding was included for afterhours/unplanned surgery, increased body mass index, reductions and manipulations performed outside of theatre, anaesthetic procedures performed by the surgeon, assistant fees and consultations during clinic visits.

The cost of implants was calculated at the average cost of the type of implant used at the current tender price, while theatre costs were calculated at the rates provided by the hospital private patient billing practice. ${ }^{[14]}$ Tariffs are billed according to category of the surgery performed.

Data were analysed using Statistica version 13 (TIBCO Software Inc., USA) and are reported as frequencies and counts or means (standard deviations (SDs)), with 95\% confidence intervals (CIs), where appropriate.

\section{Results}

The trauma theatre workload of a single orthopaedic trainee surgeon during the 3-month period included twelve 24-hour 'cutting calls', 8 additional 8 -hour trauma lists and four 8-hour local anaesthetic lists, during which a total of 157 surgical procedures were performed on 143 patients.

Surgery was mostly performed during the day $(61 \% ; n=95)$ compared with $62(39 \%)$ performed at night (19h00 - 07h00). Patients included 89 (62\%) men and 54 (38\%) women, with a mean age of 35.2 (SD 19.4) years (95\% CI 31.9 - 38.4). The age group distribution indicated a higher volume of young patients between the ages of 20 and 39 years than other age groups (Fig. 1).

A total of 117 procedures required the use of surgical implants, ranging from Kirschner wire fixation to total hip arthroplasty (Table 1). Surgical procedures were relatively evenly distributed, but procedures involving the femur and the hand accounted for $35.1 \%$ of cases (Table 1). Coding and related costs for each procedure are indicated in Table 2.

Data are expressed as the specific codes used, followed by the number of procedures performed in parentheses.

The total surgeon fees amounted to ZAR559 695.30, including the procedure fees and ZAR333.50 consultation fee per patient. The average of ZAR186 565.10 per month is double the gross salary of a registrar (ZAR91 690.00). The total implant cost was ZAR1 272667.00 and theatre fees amounted to ZAR1 301976.00 .

\section{Discussion}

The aim of this study was to review the trauma load in the public sector and to directly compare the salary of a registrar with the cost of the private remuneration

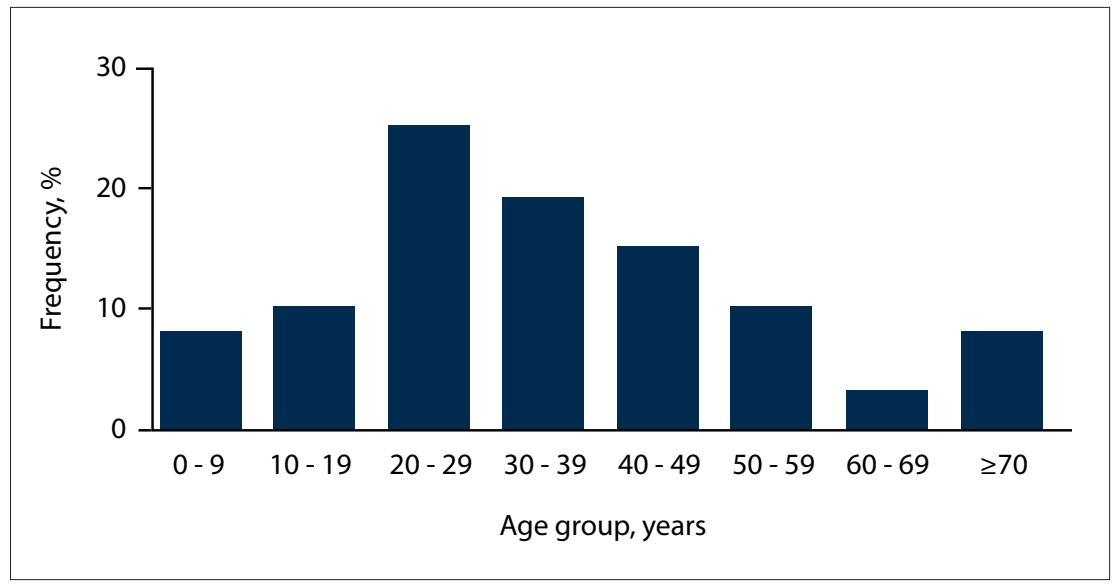

Fig. 1. Overview of age groups of patients included in the 3-month study period, operated on by a single trainee orthopaedic surgeon.

\begin{tabular}{ll} 
Table 1. Case distribution & \\
\hline Fixation method/procedure & $\boldsymbol{n}(\%)$ \\
\hline Arthroplasty & $1(0.6)$ \\
Kirschner wires & $17(10.8)$ \\
Cephalomedullary nail & $7(4.5)$ \\
Intramedullary nail & $19(12.1)$ \\
Plate fixation & $50(31.8)$ \\
Cannulated screws & $5(3.2)$ \\
External fixation & $14(8.9)$ \\
No internal fixation & $44(28.0)$ \\
Anatomical area & \\
\hline Spine & $2(1.3)$ \\
Femur & $26(16.6)$ \\
Tibia & $23(14.6)$ \\
Humerus and elbow & $16(10.2)$ \\
Forearm & $2(14.02)$ \\
Pelvis & $9(5.7)$ \\
Foot and ankle & $20(12.7)$ \\
Knee & $10(6.4)$ \\
Hands & $29(18.5)$
\end{tabular}


Table 2. Specific surgical procedures performed, with related coding

\begin{tabular}{|c|c|c|c|}
\hline Description & $\begin{array}{l}\text { Primary/secondary/tertiary } \\
\text { code }(n)\end{array}$ & $\begin{array}{l}\text { Cost per procedure, } \\
\text { ZAR }\end{array}$ & $\begin{array}{l}\text { Total cost, } \\
\text { ZAR }\end{array}$ \\
\hline \multicolumn{4}{|l|}{ Reduction with internal fixation } \\
\hline Humerus shaft with debridement & 0389/0051/0304 (2) & 2973.70 & 5947.40 \\
\hline Distal humerus & $0465 / 0051(3)$ & 4548.70 & 13646.10 \\
\hline Forearm & 0391/0051 (8) & 1919.40 & 15355.20 \\
\hline Distal radius/ulna & 0465/0051 (10) & 4548.70 & 45487.00 \\
\hline Distal radius/ulna with debridement & 0465/0051/0304 (1) & 5171.90 & 5171.90 \\
\hline Metacarpal with debridement & 0405/0051/0302 (3) & 3231.60 & 9694.80 \\
\hline Proximal phalanx with debridement and tissue repair & 0445/0051/0302 (1) & 1978.70 & 1978.70 \\
\hline Phalanx with debridement and tissue repair & 0415/0051/0302 (6) & 3028.60 & 18171.60 \\
\hline Closed reduction with Kirschner wires & $0415 / 0053(1)$ & 1670.00 & 1670.00 \\
\hline Pelvis & 0419/0051 (8) & 4947.60 & 39580.80 \\
\hline Total hip arthroplasty & $0637 / 0614(1)$ & 7178.30 & 7178.30 \\
\hline Proximal femur & $0465 / 051(10)$ & 4548.70 & 45487.00 \\
\hline Femur shaft & $0421 / 0051(6)$ & 3913.10 & 23478.60 \\
\hline Femur shaft with debridement & 0421/051/0304 (4) & 4536.30 & 18145.20 \\
\hline Distal femur & $0465 / 0051(2)$ & 4548.70 & 9097.40 \\
\hline Knee external fixation & $0465 / 0051(3)$ & 4548.70 & 13646.10 \\
\hline Knee external fixation with debridement & 0465/0051/0304 (1) & 5171.90 & 5171.90 \\
\hline Patella debridement and suture fixation & $0465 / 0302(1)$ & 4386.70 & 4386.70 \\
\hline Patella & $0465 / 0051(1)$ & 4548.70 & 4548.70 \\
\hline Proximal tibia/segmental tibia & $0465 / 0051(5)$ & 4548.70 & 22743.50 \\
\hline Tibia shaft & $0429 / 0051(5)$ & 2554.90 & 12774.50 \\
\hline Tibia shaft with debridement and muscle repair & 0429/0051/0302 (1) & 3352.60 & 3352.60 \\
\hline Tibia shaft with debridement & 0429/0051/0304 (4) & 3178.10 & 12712.40 \\
\hline Distal tibia and ankles & 0465/0051 (15) & 4548.70 & 68230.50 \\
\hline Distal tibia and ankles with debridement & 0465/0051/0304 (2) & 5171.90 & 10343.80 \\
\hline Lisfranc & $0569 / 0051(1)$ & 1919.40 & 1919.40 \\
\hline Metatarsal & 0441/0051 (1) & 1480.50 & 1480.50 \\
\hline \multicolumn{4}{|l|}{ Soft-tissue procedures } \\
\hline Arthrotomy & $0583(6)$ & 1196.30 & 7177.80 \\
\hline Synovectomy & $0592(2)$ & 1994.00 & 3988.00 \\
\hline Synovectomy with external fixation & 0592/0051 (1) & 2953.70 & 2953.70 \\
\hline Abscess & $0257(5)$ & 1084.20 & 5421.00 \\
\hline Finger abscess & $0593(6)$ & 2538.50 & 15231.00 \\
\hline Finger abscess with debridement and tissue repair & $0302(4)$ & 797.70 & 3190.80 \\
\hline Finger abscess with debridement without tissue repair & $0304(4)$ & 623.20 & 2492.80 \\
\hline Skin graft & $0304 / 0289(1)$ & 3539.20 & 3539.20 \\
\hline Quadriceps tendon repair & $0755(1)$ & 1595.20 & 1595.20 \\
\hline Extensor tendon repair & $0771(1)$ & 1616.40 & 1616.40 \\
\hline Flexor tendon repair (zone 2) & $0761(4)$ & 2417.80 & 9671.20 \\
\hline Flexor tendon/nerve repair (zone 5) & 0767/2769/0303 (1) & 4860.30 & 4860.30 \\
\hline Above-elbow amputation & $0681 / 0304(1)$ & 3259.20 & 3259.20 \\
\hline Below-knee amputation & $0699(1)$ & 2417.80 & 2417.80 \\
\hline MUA ankle & $0435(1)$ & 722.80 & 722.80 \\
\hline MUA knee & $0669(1)$ & 174.40 & 174.40 \\
\hline Removal hardware with debridement & 0304/0885/0583 (1) & 3414.70 & 3414.70 \\
\hline Costotransversectomy T7 & $0961(1)$ & 2467.40 & 2467.40 \\
\hline Transpedicular biopsy L5 & $0539(1)$ & 623.20 & 623.20 \\
\hline \multicolumn{4}{|l|}{ Paediatric reduction and Kirschner wires } \\
\hline Distal femur & 0421/051 (1) & 3352.20 & 3352.20 \\
\hline Supracondylar humerus & $0388(4)$ & 2189.60 & 8758.40 \\
\hline Radius & 0391/053 (2) & 1358.50 & 2717.00 \\
\hline Forearm MUA and POP & $0391(1)$ & 959.70 & 959.70 \\
\hline Total & & & 512004.80 \\
\hline
\end{tabular}


rate of the surgical procedures done by that registrar. No direct comparison of public and state remuneration has previously been done in SA.

The results of this study in part demonstrate the large trauma burden experienced by an orthopaedic division of a tertiary hospital. The public sector is under immense pressure owing to the large number of trauma cases. ${ }^{[15]}$ However, despite multiple dedicated lists to operate and discharge trauma patients as soon as possible, the number of patients awaiting surgery often exceeds 50 , which include those with minor trauma to severe trauma and multiple injuries. This situation leads to unacceptable delays and increases in time-sensitive complications. As a result, elective surgery lists are often sacrificed to manage the trauma load. Delays in performing urgent surgery further increase case difficulty and duration of individual surgery, making theatre use less effective. Furthermore, different surgical disciplines often make use of the same theatre space, which inevitably causes further delays when patients with life-threatening conditions need preference over less-threatening trauma cases. Although several interventions to reduce the number of these delays have been incorporated into the standard operating procedures of our unit, the increases in costs of surgical procedures, together with the high case load, lead to a global problem of not enough hands and financial support to provide the best available treatment to patients.

Currently discussed improvement strategies include:

- decentralisation through expansion of peripheral orthopaedic services

- decrease in trauma load through community upliftment and deployment of the national defence force in gang-stricken areas

- expansion of own capacity through improved efficiency, surgeon training, theatre staff training, increase in theatre staff, theatre availability and affordability of implants

- outsourcing of a percentage of trauma patients to private medical facilities and surgeons.

Our study highlights a potential solution. The current gross salary of a trainee orthopaedic surgeon is ZAR91 690.00 per month, which is $\sim 50 \%$ of the total worth of surgical procedures that a trainee performs (ZAR186 565.00). In private practice, the calculated surgeon fees are likely to be much higher, with the inclusion of codes for increased body mass index, after-hours surgery and the general billing with regard to prescribed minimum benefits. In addition, the current study did not include the use of surgical assistants, which would in practice be included regularly. This finding implies that trainee orthopaedic surgeons' work is worth significantly more than the cost to employ such a person. In 2018, the SA orthopaedic surgeonto-patient ratio was 1.63:100 000 compared with 7.4 and 8.0 for the USA and UK, respectively. ${ }^{[7]}$ Employing more registrars will not only improve service delivery, but decrease the individual load on surgeons and subsequently improve the surgeon-to-patient ratio throughout the country.

Because of the nature of orthopaedic injuries, implants are a major cost driver. Most implants are directly imported and distributed by SA branches of international companies. The complexity of cases often necessitates the use of specialised equipment, further driving the cost of procedures. Companies that supply implants have already decreased the cost of their implants for state tenders and are well regulated with long-term contracts, although increases are expected with the new tender due. General practices in individual departments need to ensure balanced and cost-effective use of implants and procedures, while maintaining clinical standards and training exposure.

In June 2017, the Government Gazette, relating to the National Health Insurance Policy, ${ }^{[11]}$ alluded to purchasing services, including the use of implants, from private hospitals and specialists - possibly at public tender prices. According to the publication, these specific contracts will only be negotiated between 2022 and 2026. The calculation of theatre fees shows a possible double financial implication, which is not only due to a loss of income but also to additional expenses if outsourced, possibly at higher rates. Therefore, expanding theatre time specifically for orthopaedic surgery might be a more cost-effective option than outsourcing.

\section{Study limitations}

The study was conducted over a short period and included only patients operated on by a single registrar, focusing on the surgeon fees involved. The billing practices vary greatly in private practice and the fees are underestimated in this study. Although all associated cost factors are not included, a significant difference in surgeon fee can be appreciated, taking into account that the theatre and implant cost will have the same trend. A more in-depth cost analysis is needed, but the current study gives an indication of the workload and case variation in an orthopaedic trauma unit.

\section{Conclusions}

In a resource-constrained environment, it is important to manage the workload effectively. Patient care and human resource management should be cost-effective, while maintaining high levels of service. Increasing public sector capacity might be a cost-effective way of achieving this goal, while selective outsourcing to private healthcare could relieve some pressure in the setting where specific expertise or equipment might be needed.

Declaration. The research for this study was done in partial fulfilment of the requirements for HFvZ's MMed (Orthopaedic Surgery) degree at Stellenbosch University.

Acknowledgements. None.

Author contributions. HvZ: study conceptualisation, data collection and analysis, first draft preparation, manuscript revision and approval of final manuscript; MB: data analysis, manuscript revision and approval of final manuscript; NF: study conceptualisation, data analysis, manuscript revision and approval of final manuscript

Funding. None.

Conflicts of interest. None.

\footnotetext{
1. Health financing profile South Africa. 2016. https://www.healthpolicyproject.com/pubs/7887/ SouthAfrica_HFP.pdf (accessed 22 April 2020).

2. Norman R, Matzopoulos R, Groenewald P, Bradshaw D. The high burden of injuries in South Africa. Bull World Health Organ 2007;85(9):695-702. https://doi.org/10.2471/BLT.06.037184

3. Statistics South Africa. Mortality and Causes of Death in South Africa, 2017. Pretoria: Stats SA, 2017.

4. Diko K. President Cyril Ramaphosa extends SANDF employment in Western Cape. 2019. https:// www.gov.za/speeches/president-cyril-ramaphosa-extends-sandf-employment-western-cape-16sep-2019-0000 (accessed 22 April 2020).

5. Case M, Thiart G, McCollum G, Roche S, Maqungo S. The burden of gunshot injuries on orthopaedic healthcare resources in South Africa. S Afr Med J 2017;107(7):626-630. https://doi.org/10.7196/ sami.2017 v107i7.12257

6. Statistics South Africa. Mid-year Population Estimates, 2019. Pretoria: Stats SA, 2019.

7. Dell AJ, Gray S, Fraser R, et al. Orthopaedic surgeon density in South Africa. World J Surg 2018;42(12):3849-3855. https://doi.org/10.1007/s00268-018-4709-4

8. South Africa. Western Cape appropriation Bill, No. B3-2018, 2018.
} 
9. South Africa. Western Cape Appropriation Bill, No. B1-2019, 2019.

10. Department of Health: Western Cape Government. Supply and Delivery of Orthopaedic Implants to the Department of Health: Western Cape Government for a Three-year Period, 2016. Cape Town: DoH, 2016. 11. South Africa. National Policy for Health Act No. 61 of 2003.

12. Government Employees Medical Scheme. 2017. https://www.gems.gov.za/en/healthcare/tools/tariffs (accessed 22 April 2020)

13. South African Orthopaedics Association. Document library. Procedures and rules. 2020. https://docs. mymembership.co.za/docmanager/2ad70cf1-4f4c-4fde-9cld-bf5e10e89d23/00147594.pdf (accessed 23 March 2021).
14. Western Cape Department of Health. Tygerberg Hospital, UPFS fee schedule for full paying patients. 2018. https://www.westerncape.gov.za/assets/departments/health/annexure_a3_full_paying tariffs_lapril_2018_0.pdf (accessed 22 April 2020).

15. Zaidi AA, Dixon J, Lupez K, et al. The burden of trauma at a district hospital in the Western Cape

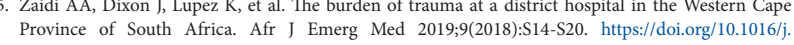
afjem.2019.01.007

Accepted 3 December 2020 